\title{
Direct and Indirect Estimates of Natural Mortality for Chesapeake Bay Blue Crab
}

\author{
David A. Hewitt, ${ }^{*}$ Debra M. Lambert, ${ }^{1}$ John M. Hoenig, and Romuald N. Lipcius \\ Department of Fisheries Science, Virginia Institute of Marine Science, College of William and Mary, \\ Post Office Box 1346, Gloucester Point, Virginia 23062-1346, USA \\ David B. Bunnell ${ }^{2}$ and Thomas J. Miller \\ University of Maryland Center for Environmental Science, Chesapeake Biological Laboratory, \\ Post Office Box 38, 1 Williams Street, Solomons, Maryland 20688, USA
}

\begin{abstract}
Analyses of the population dynamics of blue crab Callinectes sapidus have been complicated by a lack of estimates of the instantaneous natural mortality rate $(M)$. We developed the first direct estimates of $M$ for this species by solving Baranov's catch equation for $M$ given estimates of annual survival rate and exploitation rate. Annual survival rates were estimated from a tagging study on adult female blue crabs in Chesapeake Bay, and female-specific exploitation rates for the same stock were estimated by comparing commercial catches with abundances estimated from a dredge survey. We also used eight published methods based on life history parameters to calculate indirect estimates of $M$ for blue crab. Direct estimates of $M$ for adult females in Chesapeake Bay for the years 2002-2004 ranged from 0.42 to 0.87 per year and averaged 0.71 per year. Indirect estimates of $M$ varied considerably depending on life history parameter inputs and the method used. All eight methods yielded values for $M$ between 0.99 and 1.08 per year, and six of the eight methods yielded values between 0.82 and 1.35 per year. Our results indicate that natural mortality of blue crab is higher than previously believed, and we consider $M$ values between 0.7 and 1.1 per year to be reasonable for the exploitable stock in Chesapeake Bay. Remaining uncertainty about $M$ makes it necessary to evaluate a range of estimates in assessment models.
\end{abstract}

The estimation of natural mortality rates is one of the most difficult and most critical elements of many fishery stock assessments. The natural mortality rate is a key determinant of the potential productivity of a stock and thus the amount of exploitation a stock can sustain. In general, assuming that natural mortality and harvest mortality are additive, stocks with higher natural mortality rates are more productive and are able to sustain higher rates of exploitation. Lacking evidence to the contrary, most stock assessments assume that natural mortality is constant through time as well as across the sizes or ages of the exploited animals. Thus, a single estimate of the instantaneous natural mortality rate $(M)$ is presumed to apply to the entire exploitable stock.

The values used for $M$ in assessment models can have substantial effects on model results, biological

* Corresponding author: dhewitt@vims.edu

1 Present address: National Oceanic and Atmospheric Administration, National Marine Fisheries Service, 1315 East-West Highway, Silver Spring, Maryland 20910-6233, USA.

2 Present address: U.S. Geological Survey, Great Lakes Science Center, 1451 Green Road, Ann Arbor, Michigan 48105-2807, USA.

Received March 31, 2006; accepted February 25, 2007 Published online June 28, 2007 conclusions, and management recommendations. For a simple age-structured model, Clark (1999) found that stock abundance and target harvest rates could be severely overestimated when $M$ was overestimated by as little as 0.1 per year or less, especially when fishing mortality was low $(F<0.3$ per year). Similarly, harvest policies for U.S. West Coast groundfish based on a catch-at-age model were sensitive to changes in $M$ of less than 0.05 per year (Williams 2002). Using a length-structured model for red king crab Paralithodes camtschaticus in Bristol Bay, Alaska, Zheng et al. (1997a, 1997b) found that stock rebuilding and longterm harvest strategies were highly sensitive to changes in $M$ of $0.2-0.3$ per year. These and other results indicate that it is desirable to have precise knowledge about $M$ for assessment purposes.

Unfortunately, estimates of $M$ used in stock assessment models are often uncertain, partly because it is difficult and expensive to estimate the parameter. In practice, values of $M$ for use in stock assessments are obtained by two types of methods, which we refer to as direct and indirect. Direct methods involve estimating $M$ from data pertaining solely to the species or stock of interest. Direct methods include field studies designed to estimate mortality rates as well as studies that estimate $M$ as a parameter within a population dynamics model. Indirect methods involve 
making an analogy among species or stocks. If a stock of interest has life history traits that are similar to those of another group of species or stocks for which $M$ has been estimated, then it is presumed that $M$ for the stock of interest is close to $M$ for the group. For example, species with similar longevity have similar $M$ values, so longevity can be used to predict $M$ (Hoenig 1983). With direct methods, the reliability of the estimate of $M$ depends only on how reliably the parameters have been estimated for the stock of interest. For indirect methods, the reliability of the estimate of $M$ depends on three things: (1) the variability of $M$ among species or stocks with the same life history traits, (2) how well $M$ and the life history traits have been estimated for the species or stocks used to estimate the relationship between $M$ and the life history traits, and (3) how well the life history traits have been estimated for the stock of interest.

Perhaps the most feasible and reliable direct methods for estimating mortality rates are telemetry and tagging studies that can assign fates to tagged individuals; these methods have been used successfully to estimate $M$ for some fish stocks (Hampton 2000; Hightower et al. 2001; Latour et al. 2001; Heupel and Simpfendorfer 2002; Pollock et al. 2004; Waters et al. 2005; Leigh et al. 2006). It is more difficult to use tagging or telemetry methods to estimate $M$ for crustaceans, largely because crustaceans grow by molting and may shed external tags along with the old carapace during ecdysis. Tag shedding generally limits the time period and portion of the stock that can be used to estimate mortality rates. Nonetheless, a few studies have used tagging experiments to estimate mortality rates (including $M$ ) for exploited stocks of shrimp (Siddeek 1991; Xiao and McShane 2000), crabs (Siddeek et al. 2002 and references therein), and lobsters (Frusher and Hoenig 2003). Recently, Lambert et al. (2006) took advantage of the fact that female blue crabs Callinectes sapidus undergo a terminal molt at maturity to estimate survival rates for adult females in Chesapeake Bay with tag return data.

Natural mortality rates have been estimated directly for exploited crustacean stocks in several other ways. $\mathrm{Xu}$ et al. (1995a, 1995b) took advantage of fishing season closures to estimate $M$ for the green tiger prawn Penaeus semisulcatus in Kuwait based on relative abundance data from research surveys. Wang (1999) and Wang and Ellis (2005) estimated $M$ for $P$. semisulcatus in Australia with catch and effort data from a commercial fishery or length frequency data from research surveys. Fu and Quinn (2000) estimated $M$ as a parameter within a length-based population dynamics model for northern shrimp Pandalus borealis in Kachemak Bay, Alaska. Zheng et al. (1995a, 1995b) reviewed published estimates of $M$ for red king crab and also estimated it as a parameter within a lengthbased population model. Similarly, Siddeek et al. (2002) estimated $M$ within length-based and age-based population models for red king crab and golden king crab Lithodes aequispinus.

Studies of exploited lobster stocks have estimated $M$ by both direct and indirect methods. Morgan (1977) estimated $M$ for western rock lobster Panulirus cygnus in Australia by some direct methods with variable success. Annala (1977) presented some direct estimates for southern rock lobster Jasus edwardsii in New Zealand, and Thomas (1973) and Anthony (1980) reviewed both direct and indirect estimates of $M$ for American lobster Homarus americanus. Additional studies of lobsters (Sheehy et al. 1999; French McCay et al. 2003) and other exploited crustaceans (Gabche and Hockey 1995) have used indirect methods to predict $M$ based on the correlation between mortality and other life history parameters. This indirect approach is also common to fish stock assessments (Vetter 1988; Quinn and Deriso 1999).

\section{Blue Crab Natural Mortality and Stock Assessment}

The blue crab supports major commercial fisheries along the U.S. East Coast south of Connecticut and in all of the states along the Gulf of Mexico. In 2002, blue crab landings constituted approximately $7 \%$ of the global landings of true crabs, and U.S. landings have dominated the global catch of blue crab (Fogarty and Lipcius 2007). The commercial fishery for blue crab in the Chesapeake Bay is the leading contributor to the U.S. landings and is one of the most economically important fisheries in the bay. Landings from Chesapeake Bay peaked in 1966 at over 47,000 metric tons but have fallen to all-time lows in the last decade. Landings have averaged less than 25,000 metric tons since 2000 (Miller et al. 2005). The decline in landings coincides with a sustained decline in population abundance, which is partly attributable to overfishing (Lipcius and Stockhausen 2002; Bunnell and Miller 2005; Miller et al. 2005).

The estimation of $M$ has been a vexing problem for analyses of blue crab stock dynamics (Hewitt and Hoenig 2005). No direct estimates of $M$ exist for blue crab, and assessments have relied on an indirect approach for estimating $M$ based on longevity. The first formal assessment of the blue crab fishery in Chesapeake Bay (Rugolo et al. 1998) introduced an approach for estimating $M$ based on the presumed longevity of the species in an unexploited condition. Rugolo et al. (1998) used a value for longevity of 8 years and estimated $M$ to be 0.375 per year, noting that the longevity value was selected in part to provide a 
risk-averse assessment (lower $M$ ). The approach that they used to estimate $M$ was subsequently employed in other blue crab stock assessments conducted on the U.S. East Coast. Hewitt and Hoenig (2005) discussed the history and mechanics of this method and recommended that it be abandoned.

The use of longevity to estimate $M$ for blue crab has been controversial, primarily because of the uncertainty about longevity for this species. Rugolo et al. (1998) based their use of 8 years on a single tag return from an unpublished tagging study, but there was considerable disagreement among scientists, managers, and commercial fishermen about whether blue crabs could live to age 8 . Longevity values ranging from 3 to 8 years have been proposed for blue crab, but there is little evidence in support of any specific value. Aging of blue crab is difficult because individuals lack retained hard parts that may contain indications of age. Analysis of extractable lipofuscins has provided a means to age blue crabs but with only moderate precision and over a limited age range (Ju et al. 1999, 2001). An application of this technique to samples of blue crabs from Chesapeake Bay indicated that crabs older than age 2 were a minor portion of the stock but that several individuals may have been age 3 or older ( $\mathrm{Ju}$ et al. 2003). Other evidence about blue crab longevity has come from fishery-dependent tag returns in tagging studies. Despite the potential for error in the interpretation of individual tag returns, studies from North Carolina, Florida, and Chesapeake Bay have all indicated that blue crabs in exploited stocks may live to age 4 (Fischler 1965; Tagatz 1968; Lambert et al. 2006). Thus, the best available evidence suggests that blue crabs in exploited stocks can live for at least 4 years.

In support of efforts to improve scientific advice to fishery managers and to resolve some of the uncertainty about blue crab natural mortality rates, we developed and compared direct and indirect estimates of $M$ for the blue crab stock in Chesapeake Bay.

\section{Methods}

We used two approaches to estimate $M$ for blue crab: (1) direct estimation based on independent estimates of annual survival rate $(S)$ and exploitation rate $(u)$, and (2) indirect estimation based on life history parameters. Whereas the indirect estimates reflect the entire life history of the animal and thus apply to the entire stock, the direct estimates are based on the results of Lambert et al. (2006) and apply only to the adult female portion of the stock.

Direct estimates.-We used Brownie tag return models (Brownie et al. 1985) to estimate $S$ of adult female blue crabs for 2002, 2003, and 2004 based on a tagging study in Chesapeake Bay. Complete details of the tagging study and the estimation of $S$ are provided by Lambert et al. (2006); we used $S$ estimates $(\hat{S})$ based on tagging conducted in the winter. Model selection criteria indicated that the most parsimonious model was one that included a survival rate that was constant across years. However, the difference between that model and a model with separate annual estimates of survival was small (change in the quasi-likelihood Akaike's information criterion $[\triangle \mathrm{QAIC}]=3.82$ ); thus, we used separate annual estimates to obtain three estimates of $M$.

Exploitation rate is calculated as $C / N$, where $C$ is the total catch during the year and $N$ is the abundance at the start of the year. Female-specific $u$ estimates $(\hat{u})$ for Chesapeake Bay were calculated by methods described in Sharov et al. (2003) based on annual estimates of baywide abundance of exploitable female blue crabs $(\hat{N})$ and annual baywide commercial landings of female blue crabs $(\hat{C})$. Abundance was estimated from a stratified random dredge survey conducted during the winter and timed to coincide with the period in which blue crabs in northern, temperate latitudes cease molting and bury themselves in the sediment (Sharov et al. 2003; Smith and Chang 2007). Adult female blue crabs are concentrated in deeper waters in the southern portions of the bay during the winter (Jensen et al. 2005), but the dredge survey covers the entire bay. The catch per unit area was estimated for crabs that were of legal size or were going to reach legal size during the year. Absolute abundance of crabs per unit area was calculated by dividing the catch per unit area estimates by an estimate of gear efficiency (Sharov et al. 2003). Total baywide abundance was then calculated by expanding the overall mean density to the entire area of the bay $\left(9,812 \mathrm{~km}^{2}\right)$. Sex-specific estimates of $u$ were calculated by separating abundance estimates and landings by sex. The hard-shell crab sector of the fishery reports the catches of males and females separately, but the soft-shell and peeler crab sectors do not. We assumed a 1:1 sex ratio for landings reported by the soft-shell and peeler crab sectors based on fishery-dependent monitoring by the Maryland Department of Natural Resources (Fegley et al. 2006).

We used the independent estimates of $S$ and $u$ in a rearrangement of Baranov's catch equation (Ricker 1975) to solve for $M$. The catch equation is applicable to fisheries like the Chesapeake Bay blue crab fishery, in which fishing mortality and natural mortality operate concurrently (Type 2 in Ricker's terminology):

$$
C=N F A / Z,
$$

where $C$ and $N$ are as defined above, $F$ is the instantaneous fishing mortality rate per year, $Z$ is the 
TABLE 1.- Indirect methods used to estimate natural mortality rates $(M)$ for blue crab. Descriptions of the methods and sources of input parameter estimates are discussed in the text.

\begin{tabular}{|c|c|c|c|c|}
\hline Method & Source(s) & Equation $^{\mathrm{a}}$ & $\begin{array}{l}\text { Input parameter } \\
\text { estimates }\end{array}$ & $M$ range \\
\hline 1 & $\begin{array}{l}\text { Charnov and Berrigan } \\
\text { (1990), Charnov } \\
\text { (1993), Jensen } \\
\text { (1996) }\end{array}$ & $M=X / t_{m}$ & $\begin{array}{c}t_{m}=1.00-1.67 \\
X=1.65-2.20\end{array}$ & $0.99-2.20$ \\
\hline 2 & $\begin{array}{l}\text { Charnov (1993), } \\
\text { Jensen (1996) }\end{array}$ & $M=X \cdot K$ & $\begin{array}{c}K=0.47-1.09 \\
X=1.50-1.65\end{array}$ & $0.71-1.80$ \\
\hline 3 & $\begin{array}{l}\text { Alverson and Carney } \\
\text { (1975) }\end{array}$ & $M=3 K /\left(e^{0.38 K t_{\max }}-1\right)$ & $\begin{array}{c}K=0.47-1.09 \\
t_{\max }=4-6\end{array}$ & $0.30-1.35$ \\
\hline 4 & Hoenig (1983) & $M=e^{1.44-0.982 \log _{e}\left(t_{\max }\right)}$ & $t_{\max }^{\max }=4-6$ & $0.73-1.08$ \\
\hline 5 & Pauly (1980) & $\begin{array}{l}\log M=-0.0066-0.279 \log \left(C W_{\infty}\right) \\
\quad+0.6543 \log K+0.4634 \log T\end{array}$ & $\begin{array}{l}K=0.47-1.09 \\
C W_{\infty}=17.6-23.5 \\
T=16.5\end{array}$ & $0.91-1.72$ \\
\hline 6 & Pauly (1980) & $\begin{array}{l}\log M=-0.2107-0.0824 \log \left(W_{\infty}\right) \\
\quad+0.6757 \log K+0.4627 \log T\end{array}$ & $\begin{array}{l}K=0.47-1.09 \\
W_{\infty}=231-464 \\
T=16.5\end{array}$ & $0.82-1.52$ \\
\hline 7 & Roff (1984) & $M=3 K /\left(e^{K t_{m}}-1\right)$ & $\begin{array}{l}K=0.47-1.09 \\
t_{m}=1.00-1.67\end{array}$ & $0.63-2.35$ \\
\hline 8 & Lorenzen (1996) & $M=3.00 W^{-0.288}$ & $W \stackrel{m}{=} 25.0-450.0$ & $0.52-1.19$ \\
\hline
\end{tabular}

${ }^{\mathrm{a}} t_{m}=$ age at maturity (years); $X=$ a constant taken from the given sources; $K=$ von Bertalanffy growth coefficient (per year); $t_{\max }=$ longevity (years); $C W_{\infty}=$ asymptotic maximum carapace width $(\mathrm{cm})$ from the von Bertalanffy growth model; $T=$ grand annual mean of water temperature $\left({ }^{\circ} \mathrm{C}\right)$ recorded at the Virginia Institute of Marine Science (Gloucester Point), 1990-2003; $W_{\infty}=$ asymptotic maximum weight (g) from the von Bertalanffy growth model; $W=$ wet weight $(\mathrm{g})$.

instantaneous total mortality rate per year, $A$ is the total annual mortality rate $\left(1-S ; S\right.$ is equal to $e^{-Z}$, where $e$ is the base of natural logarithms), and $Z$ equals $M+F$. Given that $u$ is equal to $C / N$, the equation can be rearranged to solve for $F$ as $(u Z) / A$. By subtraction, $M$ is equal to $Z-[(u Z) / A]$.

Annala (1977) used this general approach for the southern rock lobster, and Kahn and Helser (2005) employed it in an assessment of the blue crab stock in Delaware Bay. Similar to Lambert et al. (2006), Annala (1977) estimated $Z$ from tag returns obtained from a commercial fishery. He calculated $M$ by the approach presented here but concluded that the approach substantially overestimated $M$ because of tagging effects, such as tagging-related mortality and tag loss. Lambert et al. (2006) indicated that their study did not violate any of the assumptions of the Brownie models, which include these potential biases; we therefore believe the approach is appropriate for our situation. Kahn and Helser (2005) did not use data from a tagging study; rather, they used relative abundance data from a research survey and a catch-survey model to estimate $u$ and $Z$.
Indirect estimates.-We selected eight published indirect methods that are commonly used in fishery stock assessments to obtain ranges of $M$ estimates for blue crab (Table 1). Most of the methods were developed primarily for fish and included little data on invertebrates. We recognize the uncertainty associated with using indirect methods that have been derived from data on many species to predict $M$ for a single species (Vetter 1988; Pascual and Iribarne 1993). The use of multiple methods may reduce the bias imposed by any one method.

The indirect methods rely on parameters that are commonly measured in biological studies, including average age at maturity $\left(t_{m}\right)$, longevity $\left(t_{\text {max }}\right)$, body size, and the parameters of the von Bertalanffy growth model (Brody growth coefficient $[K]$ and asymptotic maximum size in length $\left[L_{\infty}\right]$ or weight $\left.\left[W_{\infty}\right]\right)$. For blue crabs, the carapace width $(C W ; \mathrm{mm})$ between the points of the lateral spines was substituted for length (thus, $\left.C W_{\infty}=L_{\infty}\right)$. Although considerable research has been conducted into models that account for the discontinuous nature of crustacean growth (reviewed in Smith and Chang 2007), the simpler von Bertalanffy model has been used in many studies of blue crab stocks and 
provides a reasonable approximation (Bunnell and Miller 2005). Estimates of blue crab life history parameters drawn from the literature and unpublished data were selected to represent the Chesapeake Bay stock (Table 1). Whenever possible, we used empirically derived parameter estimates as opposed to estimates based on model inference. For example, we used a range of published estimates for the von Bertalanffy growth model parameters but only included those derived from field data. Two of the indirect methods required estimates of $t_{\max }$, for which we used a range of 4-6 years.

Methods 1 and 2 (Table 1), based on simple empirical relationships between $M$ and the parameters $t_{m}$ and $K$, are built on the work of Beverton and Holt (1959) and Beverton (1963, 1992). Charnov (1993) extended this work and compiled data showing that certain relationships among life history parameters were generally stable within broad taxonomic boundaries. He reasoned that the relationships probably arose from evolutionary tradeoffs. Jensen (1996) derived the same relationships directly from theory, showing that they resulted from a tradeoff between mortality and reproduction when a species evolved to maximize its lifetime fecundity. Jensen (1996) estimated values for the relationships that were somewhat different than those determined by Charnov (1993). We used a range of 1.00-1.67 years as input parameter estimates for $t_{m}$, based on Van Engel (1958) and Lippson (1973). Charnov (1993) used the data compiled by Pauly (1980), which was also used to develop methods 5 and 6 (Table 1).

Method 3 is taken from Alverson and Carney (1975), in which a theoretical model was developed to predict the age at which a cohort of fish would maximize its collective biomass if growth followed a von Bertalanffy model. They also included an empirical regression model based on 63 fish species to relate $t_{\max }$ to the age at which the cohort would maximize its biomass. The first model includes a term for $M$, and the two models can be combined and rearranged to solve for $M$ given estimates of $K$ and $t_{\max }$.

Method 4, from Hoenig (1983), is a simple linear regression of $\log _{e}(Z)$ against $\log _{e}\left(t_{\max }\right)$. The data showed that $Z$ was inversely related to $t_{\max }$. Because the 134 stocks in the data set were either unexploited or lightly exploited, $Z$ approximates $M$. Although this method relies solely on an estimate of $t_{\max }$, we used it because it was based on an extensive data set of diverse taxa, including fish, cetaceans, and mollusks.

Methods 5 and 6, multiple linear regressions developed by Pauly (1980), are two of the most common methods used in stock assessments to predict $M$. The regressions were based on 175 stocks of freshwater and marine fish species. Each of the regression equations relates $M$ to parameter estimates from the von Bertalanffy growth model and the average temperature of the water in which the stock lives. Separate equations are used for growth models fit to length and weight data. Charnov (1993) and Jensen (1996) showed that temperature added little to the predictive capability of the regressions, but we used them in their original form. We converted $C W_{\infty}(\mathrm{mm})$ to $W_{\infty}$ (g) using the following allometric equation (Miller et al. 2005):

$$
W=0.000842 \cdot C W^{2.422} .
$$

Method 7 is taken from Roff (1984), who explored theoretically the evidence that life history parameters were consistently correlated among teleost fishes. In part of his investigation (elaborated on by Jensen 1996), Roff (1984) assumed that evolution had shaped life history parameters to maximize lifetime fecundity through tradeoffs among growth, reproduction, and survival. He determined that the optimal $t_{m}$ could be estimated from its relationship with $K$ and $M$. Similar to method 3, the model can be rearranged to solve for $M$ given estimates of $K$ and $t_{m}$. Roff (1984) showed that this model had reasonable predictive capability when tested with data from 30 stocks, most of which were taken from $\mathrm{Ni}$ (1978). In addition, the predictive capability was similar to that of the length-based regression of Pauly (1980) when tested with a subset of 17 stocks. Interestingly, the equation Roff (1984) developed was the same as that used by Alverson and Carney (1975) to solve for the age at which a cohort would maximize its biomass, implying that the optimal $t_{m}$ is the same as the age at which a cohort maximizes its biomass.

Lastly, method 8, taken from Lorenzen (1996), predicts $M$ based on its inverse relationship with body size. This method allows $M$ to vary among individuals; however, we used it with a range of sizes for exploitable blue crabs $(>76 \mathrm{~mm} \mathrm{CW})$ to produce a range of $M$ estimates in a way similar to the other methods. Peterson and Wroblewski (1984) concluded that mortality due to predation in pelagic marine ecosystems was a power function of body weight. Lorenzen (1996) related estimates of $M$ to wet body weight for a large and diverse data set for fishes of all sizes in natural ecosystems (lakes, rivers, marine systems) and also found that $M$ was a power function of body weight. The relationship did not differ statistically among ecosystems or latitudinal zones. We used the Lorenzen (1996) equation estimated for all natural ecosystems combined and provided a range of blue crab weights by converting carapace widths using equation (2). 
TABLE 2.-Annual estimates of survival rate $(S)$ and exploitation rate $(u)$ and resulting estimates of instantaneous fishing $(F)$ and natural $(M)$ mortality rates (per year) for adult female blue crabs in Chesapeake Bay. The estimates of $S$ are based on the tagging study described by Lambert et al. (2006). The $95 \%$ confidence intervals (CIs) for $\hat{S}$ are given in parentheses.

\begin{tabular}{ccccc}
\hline Year & $\hat{S}(95 \% \mathrm{CI})$ & $\hat{u}$ & $\hat{F}$ & $\hat{M}$ \\
\hline 2002 & $0.091(0.011-0.475)$ & 0.748 & 1.974 & 0.423 \\
2003 & $0.097(0.028-0.291)$ & 0.578 & 1.493 & 0.840 \\
2004 & $0.069(0.022-0.196)$ & 0.628 & 1.803 & 0.871 \\
\hline
\end{tabular}

\section{Direct Estimates}

\section{Results}

Survival rates of adult female blue crabs in Chesapeake Bay were exceptionally low but consistent. We estimated $S$ to be 0.091 in 2002, 0.097 in 2003, and 0.069 in 2004 (Table 2). The 95\% confidence intervals for $\hat{S}$ are wide because a variance inflation factor was used to adjust the standard errors of the estimates. The adjustment was necessary because two long-term recaptures of tagged crabs caused the model to fit poorly; these long-term recaptures are possible but unlikely given the $S$ estimates. The standard errors for $\hat{S}$ were much lower when these recaptures were excluded. For example, the $95 \%$ confidence interval for the estimate in 2002 was $0.017-0.160$ without the two long-term recaptures. However, there was no reason to exclude these recaptures, so they were included in the analysis (Lambert et al. 2006). The adjusted confidence intervals may overstate the uncertainty in $\hat{S}$. Female-specific $\hat{u}$ calculated from the dredge survey abundances and commercial landings of female blue crabs varied from 0.578 to 0.748 , reflecting intense fishing pressure. Solving Baranov's catch equation for $M$ with $\hat{S}$ and $\hat{u}$ yielded $M$ estimates ranging from 0.423 per year in 2002 to 0.871 per year in 2004 (mean $=0.711$ per year). The estimate for 2002 was about $50 \%$ of the 2003 and 2004 estimates.

\section{Indirect Estimates}

The indirect methods collectively provided a broad range of $M$ estimates (0.30-2.35 per year; Table 1). The lowest estimates were given by method 3 with $t_{\max }$ of 6 years and $K$ of 1.09 per year. The range of estimates from this method was wider than that from method 4, which only used $t_{\max }$. Methods 1 and 2 produced similar ranges of values and included among the highest estimates (only method 7 gave higher estimates). Methods 5 and 6 produced similar ranges of estimates, roughly in the middle of the collective range. Estimates from method 8, based on weight, were similar to those from method 3 and were nearly

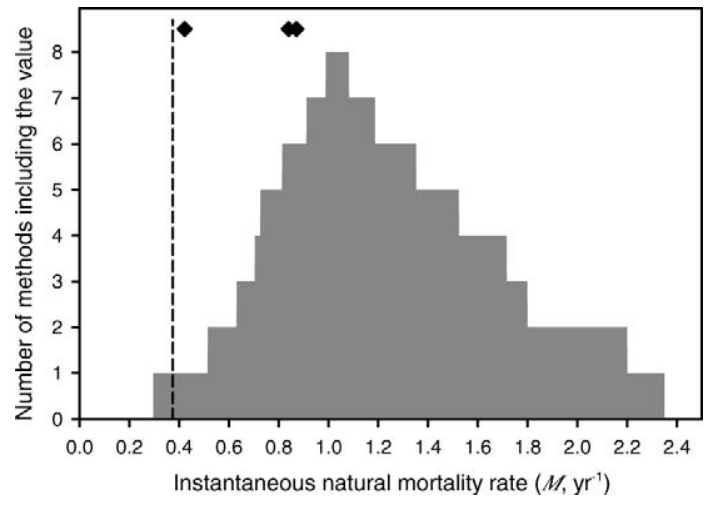

FiguRE 1.-Number of indirect estimation methods in Table 1 (out of eight possible methods) that yielded given values ( $x$ axis) of instantaneous natural mortality rate $(M)$ for blue crab. The direct estimates of $M$ for adult females in Chesapeake Bay from our study (2002-2004) are indicated by diamonds. The vertical dashed line indicates the $M$ value $(0.375$ per year) used by Rugolo et al. (1998).

identical to estimates based on the more theoretical approach of Peterson and Wroblewski (1984). Although we did not include their approach in Table 1, it would add weight to $M$ estimates in the range of $0.5-1.2$ per year. The collective range of the $M$ estimates was extensive, but all eight methods yielded values between 0.99 and 1.08 per year, and six methods gave estimates between 0.82 and 1.35 per year (Figure 1).

\section{Discussion}

The direct estimates of $M$ for adult female blue crabs in Chesapeake Bay represent the first direct estimates for this species that are applicable at the scale of a stock assessment. The direct estimates for 2003 ( 0.84 per year) and 2004 ( 0.87 per year) are close to the region of central tendency given by the indirect methods (0.99-1.08 per year). Collectively, the direct and indirect estimates indicate that values between 0.7 and 1.1 per year are reasonable estimates of $M$ for the exploitable stock of blue crab in Chesapeake Bay. Estimates at the upper end of this range are further supported by the results from the catch-multiplesurvey assessment model of Miller et al. (2005), in which process error and the sum of the squared residuals were minimized at $M$ values between 1.00 and 1.25 per year. We suggest that stock assessments for blue crab consider a range of reasonable $M$ values to account for remaining uncertainty about the parameter.

Overall, our results indicate that $M$ for the blue crab in Chesapeake Bay, though still uncertain, is higher than previously assumed. The estimate of 0.375 per 
year used by Rugolo et al. (1998) does not appear to be credible. Only one indirect method (Alverson and Carney 1975) produced values as low as 0.375 per year and only when extreme values for life history parameters were used (high $K$, high $t_{\max }$ ). None of the direct estimates were as low as 0.375 per year. In addition, with an $M$ of 0.375 per year, the catchmultiple-survey assessment model failed to adequately fit the time series of $\hat{u}$ observed in the fishery (Miller et al. 2005). From an evolutionary perspective, higher natural mortality rates are consistent with other blue crab life history features, such as fast growth, early maturity, and a relatively short life span (Adams 1980; Gunderson and Dygert 1988).

Changing the estimate of $M$ for blue crab from 0.375 per year to $0.7-1.1$ per year reflects a significant shift in our understanding of the population dynamics of this species. The higher estimates imply that the exploitable stock is composed primarily of one or two year-classes, which is consistent with the findings of Ju et al. (2003). As a result, the age structure of the stock and the ability of the stock to support the fisheries are heavily dependent on the magnitude of annual recruitment.

We recognize several potential concerns with estimating $M$ by using $\hat{S}$ from the tagging study together with the female-specific $\hat{u}$. First, unlike $\hat{S}, \hat{u}$ did not account for recreational removals. However, the recreational removals of blue crabs in Chesapeake Bay are believed to be less than $10 \%$ of the commercial harvest (Ashford and Jones 2003). Second, the tagging study included only adult females that had undergone their terminal molt, whereas $\hat{u}$ was calculated for all females that were of legal size or would become legal size during the year. A portion of the exploitable females would not have undergone their terminal molt (Bunnell and Miller 2005). Finally, the periods to which $\hat{S}$ and $\hat{u}$ applied were not exactly matched. The $\hat{S}$ applied to an annual period beginning in October or November (Lambert et al. 2006), whereas $\hat{u}$ applied to calendar years. Overall, we expect that the small difference in timing of the two estimates introduced little error into the estimates of $M$.

The range of $M$ estimates based on the indirect methods (0.30-2.35 per year) is considerably wider than ranges generated by similar but smaller sets of indirect methods applied to fish stocks (Gunderson et al. 2003; Bacheler et al. 2005; Fischer et al. 2005). One reason for this is the relatively short life span of blue crab; that is, $M$ varies considerably with small changes in parameters such as $t_{\max }$ and $t_{m}$ for shortlived animals. For example, Simpfendorfer (1999a) applied five indirect methods to a small, short-lived shark species (maximum age $=6-7$ years) and produced a range of $M$ estimates from 0.60 to 1.65 per year. In contrast, Simpfendorfer (1999b) and Heupel and Simpfendorfer (2002) used suites of indirect methods for larger, longer-lived species and found that estimates of $M$ varied among methods by less than 0.25 per year. Another reason for the wide range of $M$ estimates for blue crab is the variability in estimates of the von Bertalanffy growth model parameters, which are used in five of the eight methods. The range of estimates we used for $K$ and $C W_{\infty}$ accurately reflects the high variability in blue crab growth rates (Ju et al. 2001).

Uncertainty appears to be a persistent feature of our understanding of natural mortality in crab stocks. In a study of red king crab, blue king crab $P$. platypus, and golden king crab, Siddeek et al. (2002) obtained point estimates of $M$ ranging from 0.19 to 0.70 per year depending on the species and sex. They used a jackknife procedure to determine the precision of the estimates, and all of the $95 \%$ confidence intervals included zero. The confidence intervals spanned ranges of values that were 2.7-4.3 times the point estimates. They also concluded that some of the point estimates were unreasonable considering the life expectancy of the animals. Similarly, Zheng (2003) concluded that a study of $M$ for snow crab Chionoecetes opilio in the Bering Sea did little to resolve the large uncertainty about $M$ for this species.

Some of what appears to be uncertainty in our estimates of $M$ for blue crab may actually be true variability in $M$. Ecological studies of blue crabs offer strong evidence that natural mortality rates vary considerably with respect to a variety of factors such as sex, size, habitat, and season (Heck and Wilson 1987; Lipcius et al. 2005). However, it is difficult to apply the findings of such small-scale ecological studies at the scale of stock assessments; a good example is provided by Incze et al. (2003) for the American lobster. Nonetheless, the suggestion to specifically include variability in $M$ in assessment models continues to be repeated in the literature, often in connection with evidence demonstrating such variability (Gulland 1987; Vetter 1988; Fu and Quinn 2000; Hampton 2000; Tanasichuk 2000).

Studies of some exploited crustacean stocks have revealed various sources of variability in $M$ and have included such variability in population dynamics models. Xiao and McShane (2000) found that $M$ varied with size or between sexes for the western king prawn Penaeus latisulcatus, but size and sex were confounded such that it was unclear which factor was the important one. Year-specific estimates of $M$ for northern shrimp in Kachemak Bay, Alaska, showed an increasing trend through time, which may have resulted from increasing predation pressure from groundfish $(\mathrm{Fu}$ 
and Quinn 2000). Based on a review of previously published estimates, Zheng et al. (1995a) concluded that $M$ was lower for intermediate-size red king crabs than it was for smaller and larger crabs and that $M$ varied substantially over time. Thus, they included effects of sex, size, and year on $M$ for red king crab in a population dynamics model. Concerns about overparameterization of the model led them to develop a more parsimonious version that removed the size dependence in $M$, but results were similar (Zheng et al. 1995b). Siddeek et al. (2002) estimated $M$ separately for male and female king crabs, but attempts to estimate $M$ by year were unsuccessful. Studies that attempt to estimate $M$ within a population dynamics model may be hampered by the common problem of $M$ being confounded with other model parameters (Schnute and Richards 1995; Clark 1999; Wang 1999; Fu and Quinn 2000). Such a problem was at least partly to blame for the inconclusive results of Zheng (2003).

Consistent with a limited understanding of natural mortality, previous assessments of blue crab stocks have not included variability in $M$. However, $M$ probably varies between sexes, across sizes of crabs in the exploitable stock, or through time. Indeed, one of the indirect methods we considered in this study provided estimates of $M$ that varied by weight, where $M$ was higher for smaller animals (Lorenzen 1996). The general concordance between the direct estimates we obtained for adult females and the indirect estimates suggests that the direct estimates may also apply to males and larger immature crabs that are captured by the fishery. However, values of $\hat{u}$ are higher for females than for males (Miller et al. 2005), and more research is needed to determine whether $\hat{S}$ values for adult females are applicable to the rest of the stock. As for variation in $M$ through time, our direct estimates of $M$ for adult females do not have associated measures of precision, so we do not know whether the low value in 2002 reflects a real change in $M$ or simply measurement error.

In the future, blue crab stock assessments will need to use higher estimates of $M$ and will need to evaluate a range of estimates to account for uncertainty about the parameter. Assessments may also need to account for variability in $M$ to be realistic and provide reliable management advice. Given the limited direct evidence about such variability, developments in assessment techniques will need to proceed incrementally and be accompanied by further research.

\section{Acknowledgments}

We thank the other members of the 2005 Chesapeake Bay blue crab stock assessment team (C. Bonzek, G.
Davis, L. Fegley, S. J. D. Martell, and A. Sharov) for their helpful advice, especially L. Fegley for providing the estimates of sex-specific exploitation rates. D. Vaughan of the National Oceanic and Atmospheric Administration (NOAA) Beaufort Laboratory in North Carolina assisted in locating some of the indirect methods, and D. Kahn of the Delaware Department of Natural Resources and Environmental Control provided helpful comments. The comments and suggestions of two anonymous reviewers improved the manuscript substantially. The Chesapeake Bay blue crab stock assessment was supported by funding from the NOAA Chesapeake Bay Office Fisheries Program (award number NA03NMF4570376), as was the tagging study on adult females (award number NA17FU1655). D.A.H. gratefully acknowledges the support of the Willard A. Van Engel (WAVE) Fellowship for Crustacean Research; D.B.B. was supported by funding from Maryland Sea Grant (award number NA05OAR4171042). This paper is contribution 2816 of the Virginia Institute of Marine Science, College of William and Mary; contribution 4066 of the University of Maryland Center for Environmental Science, Chesapeake Biological Laboratory; and contribution 1416 of the U.S. Geological Survey Great Lakes Science Center.

\section{References}

Adams, P. B. 1980. Life history patterns in marine fishes and their consequences for fisheries management. U.S. National Marine Fisheries Service Fishery Bulletin 78:1-12.

Alverson, D. L., and M. J. Carney. 1975. A graphic review of the growth and decay of population cohorts. Journal du Conseil International pour l'Exploration de la Mer 36:133-143.

Annala, J. H. 1977. Effects of increases in the minimum legal size on the Otago rock lobster fishery. New Zealand Fisheries Research Division Occasional Publication 13.

Anthony, V. C. 1980. Review of lobster mortality estimates in the United States. Canadian Technical Report of Fisheries and Aquatic Sciences 932:17-25.

Ashford, J. R., and C. M. Jones. 2003. Survey of the blue crab recreational fishery in Maryland and Virginia, 2002. Final report from Old Dominion University to the National Oceanic and Atmospheric Administration Chesapeake Bay Office, Annapolis, Maryland.

Bacheler, N. M., R. A. Wong, and J. A. Buckel. 2005. Movements and mortality rates of striped mullet in North Carolina. North American Journal of Fisheries Management 25:361-373.

Beverton, R. J. H. 1963. Maturation, growth and mortality of clupeid and engraulid stocks in relation to fishing. Rapports et Procès-Verbaux des Réunions, Conseil International pour l'Exploration de la Mer 154:44-67.

Beverton, R. J. H. 1992. Patterns of reproductive strategy parameters in some marine teleost fishes. Journal of Fish Biology 41(Supplement B):137-160.

Beverton, R. J. H., and S. J. Holt. 1959. A review of the 
lifespans and mortality rates of fish in nature, and their relation to growth and other physiological characteristics. Pages 142-177 in G. E. W. Westenholme and M. O'Connor, editors. The lifespan of animals, CIBA Foundation colloquia on ageing, volume 5. Little, Brown and Company, Boston.

Brownie, C., D. R. Anderson, K. P. Burnham, and D. S. Robson. 1985. Statistical inference from band recovery data: a handbook, 2nd edition. U.S. Fish and Wildlife Service Resource Publication 156. Available: www. warnercnr.colostate.edu/class_info/fw663/Brownie1985/ BrownieList.html. (May 2007).

Bunnell, D. B., and T. J. Miller. 2005. An individual-based modeling approach to spawning-potential per-recruit models: an application to blue crab (Callinectes sapidus) in Chesapeake Bay. Canadian Journal of Fisheries and Aquatic Sciences 62:2560-2572.

Charnov, E. L. 1993. Life history invariants: some explorations of symmetry in evolutionary ecology. Oxford University Press, New York.

Charnov, E. L., and D. Berrigan. 1990. Dimensionless numbers and life history evolution: age of maturity versus the adult lifespan. Evolutionary Ecology 4:273-275.

Clark, W. G. 1999. Effects of an erroneous natural mortality rate on a simple age-structured stock assessment. Canadian Journal of Fisheries and Aquatic Sciences 56:1721-1731.

Fegley, L. W., B. K. Davis, G. R. Davis, K. Webb, J. C. Walstrum, and H. R. Brown. 2006. Harvest and effort characterization of the Maryland Chesapeake Bay blue crab fishery through a cooperative data collection program. Final report from the Maryland Department of Natural Resources to the National Oceanic and Atmospheric Administration Chesapeake Bay Office, Annapolis, Maryland.

Fischer, A. J., M. S. Baker, Jr., C. A. Wilson, and D. L. Nieland. 2005. Age, growth, mortality, and radiometric age validation of gray snapper (Lutjanus griseus) from Louisiana. U.S. National Marine Fisheries Service Fishery Bulletin 103:307-319.

Fischler, K. J. 1965. The use of catch-effort, catch-sampling, and tagging data to estimate a population of blue crabs. Transactions of the American Fisheries Society 94: 287-310.

Fogarty, M. J., and R. N. Lipcius. 2007. Population dynamics and fisheries. Pages 711-755 in V. S. Kennedy and L. E. Cronin, editors. The blue crab Callinectes sapidus. University of Maryland Sea Grant College, College Park.

French McCay, D. P., M. Gibson, and J. S. Cobb. 2003. Scaling restoration of American lobsters: combined demographic and discounting model for an exploited species. Marine Ecology Progress Series 264:177-196.

Frusher, S. D., and J. M. Hoenig. 2003. Recent developments in estimating fishing and natural mortality and tag reporting rate of lobsters using multi-year tagging models. Fisheries Research 65:379-390.

Fu, C., and T. J. Quinn II. 2000. Estimability of natural mortality and other population parameters in a lengthbased model: Pandalus borealis in Kachemak Bay, Alaska. Canadian Journal of Fisheries and Aquatic Sciences 57:2420-2432.

Gabche, C. E., and H.-U. P. Hockey. 1995. Growth and mortality of the giant African river prawn Macrobrachium vollenhovenii (Herklots: Crustacea, Palaemonidae) in the Lobe River, Cameroon: a preliminary evaluation. Journal of Shellfish Research 14:185-190.

Gulland, J. A. 1987. Natural mortality and size. Marine Ecology Progress Series 39:197-199.

Gunderson, D. R., and P. H. Dygert. 1988. Reproductive effort as a predictor of natural mortality rate. Journal du Conseil International pour 1'Exploration de la Mer 44:200-209.

Gunderson, D. R., M. Zimmerman, D. G. Nichol, and K. Pearson. 2003. Indirect estimates of natural mortality rate for arrowtooth flounder (Atheresthes stomias) and darkblotched rockfish (Sebastes crameri). U.S. National Marine Fisheries Service Fishery Bulletin 101:175-182.

Hampton, J. 2000. Natural mortality rates in tropical tunas: size really does matter. Canadian Journal of Fisheries and Aquatic Sciences 57:1002-1010.

Heck, K. L., Jr., and K. A. Wilson. 1987. Predation rates on decapod crustaceans in latitudinally separated seagrass communities: a study of spatial and temporal variation using tethering techniques. Journal of Experimental Marine Biology and Ecology 107:87-100.

Heupel, M. R., and C. A. Simpfendorfer. 2002. Estimation of mortality of juvenile blacktip sharks, Carcharhinus limbatus, within a nursery area using telemetry data. Canadian Journal of Fisheries and Aquatic Sciences 59:624-632.

Hewitt, D. A., and J. M. Hoenig. 2005. Comparison of two approaches for estimating natural mortality based on longevity. U.S. National Marine Fisheries Service Fishery Bulletin 103:433-437.

Hightower, J. E., J. R. Jackson, and K. H. Pollock. 2001. Use of telemetry methods to estimate natural and fishing mortality of striped bass in Lake Gaston, North Carolina. Transactions of the American Fisheries Society 130: 557-567.

Hoenig, J. M. 1983. Empirical use of longevity data to estimate mortality rates. U.S. National Marine Fisheries Service Fishery Bulletin 82:898-903.

Incze, L. S., N. Wolff, and R. A. Wahle. 2003. Can scientific observations of early life stages be scaled up to the level of a fished population? A case study using Homarus americanus. Fisheries Research 65:33-46.

Jensen, A. L. 1996. Beverton and Holt life history invariants result from optimal trade-off of reproduction and survival. Canadian Journal of Fisheries and Aquatic Sciences 53:820-822.

Jensen, O. P., R. Seppelt, T. J. Miller, and L. J. Bauer. 2005. Winter distribution of blue crab Callinectes sapidus in Chesapeake Bay: application and cross-validation of a two-stage generalized additive model. Marine Ecology Progress Series 299:239-255.

Ju, S.-J., D. H. Secor, and H. R. Harvey. 1999. Use of extractable lipofuscin for age determination of blue crab. Marine Ecology Progress Series 185:171-179.

Ju, S.-J., D. H. Secor, and H. R. Harvey. 2001. Growth rate variability and lipofuscin accumulation rates in the blue crab Callinectes sapidus. Marine Ecology Progress Series 224:197-205.

Ju, S.-J., D. H. Secor, and H. R. Harvey. 2003. Demographic assessment of the blue crab (Callinectes sapidus) in 
Chesapeake Bay using extractable lipofuscins as age markers. U.S. National Marine Fisheries Service Fishery Bulletin 101:312-320.

Kahn, D. M., and T. E. Helser. 2005. Abundance, dynamics and mortality rates of the Delaware Bay stock of blue crabs, Callinectes sapidus. Journal of Shellfish Research 24:269-284.

Lambert, D. M., J. M. Hoenig, and R. N. Lipcius. 2006. Tag return estimation of annual and semiannual survival rates of adult female blue crabs. Transactions of the American Fisheries Society 135:1592-1603.

Latour, R. J., K. H. Pollock, C. A. Wenner, and J. M. Hoenig. 2001. Estimates of fishing and natural mortality for subadult red drum in South Carolina waters. North American Journal of Fisheries Management 21:733-744.

Leigh, G. M., W. S. Hearn, and K. H. Pollock. 2006. Timedependent instantaneous mortality rates from multiple tagging experiments with exact times of release and recovery. Environmental and Ecological Statistics 13: 89-108.

Lipcius, R. N., R. D. Seitz, M. S. Seebo, and D. ColonCarrion. 2005. Density, abundance and survival of the blue crab in seagrass and unstructured salt marsh nurseries of Chesapeake Bay. Journal of Experimental Marine Biology and Ecology 319:69-80.

Lipcius, R. N., and W. T. Stockhausen. 2002. Concurrent decline of the spawning stock, recruitment, larval abundance, and size of the blue crab Callinectes sapidus in Chesapeake Bay. Marine Ecology Progress Series 226:45-61.

Lippson, R. L. 1973. Blue crab. Pages 26-27 in A. J. Lippson, editor. The Chesapeake Bay in Maryland: an atlas of natural resources. Johns Hopkins University Press, Baltimore.

Lorenzen, K. 1996. The relationship between body weight and natural mortality in juvenile and adult fish: a comparison of natural ecosystems and aquaculture. Journal of Fish Biology 49:627-647.

Miller, T. J., S. J. D. Martell, D. B. Bunnell, G. Davis, L. Fegley, A. Sharov, C. Bonzek, D. Hewitt, J. Hoenig, and R. N. Lipcius. 2005. Stock assessment of the blue crab in Chesapeake Bay, 2005. University of Maryland Center for Environmental Science, Technical Report Series TS487-05, Solomons. Available: hjort.cbl.umces.edu/crabs/ Assessment05.html. (May 2007).

Morgan, G. R. 1977. Aspects of the population dynamics of the western rock lobster and their role in management. Doctoral dissertation. University of Western Australia, Nedlands.

Ni, I.-H. 1978. Comparative fish population studies. Doctoral dissertation. University of British Columbia, Vancouver.

Pascual, M. A., and O. O. Iribarne. 1993. How good are empirical predictions of natural mortality? Fisheries Research 16:17-24.

Pauly, D. 1980. On the interrelationships between natural mortality, growth parameters, and mean environmental temperature in 175 fish stocks. Journal du Conseil International pour l'Exploration de la Mer 39:175-192.

Peterson, I., and J. S. Wroblewski. 1984. Mortality rate of fishes in the pelagic ecosystem. Canadian Journal of Fisheries and Aquatic Sciences 41:1117-1120.

Pollock, K. H., H. Jiang, and J. E. Hightower. 2004.
Combining telemetry and fisheries tagging models to estimate fishing and natural mortality rates. Transactions of the American Fisheries Society 133:639-648.

Quinn, T. J. II, and R. B. Deriso. 1999. Quantitative fish dynamics. Oxford University Press, New York.

Ricker, W. E. 1975. Computation and interpretation of biological statistics of fish populations. Fisheries Research Board of Canada Bulletin 191.

Roff, D. A. 1984. The evolution of life history parameters in teleosts. Canadian Journal of Fisheries and Aquatic Sciences 41:989-1000.

Rugolo, L. J., K. S. Knotts, A. M. Lange, and V. A. Crecco. 1998. Stock assessment of Chesapeake Bay blue crab (Callinectes sapidus Rathbun). Journal of Shellfish Research 17:493-517.

Schnute, J. T., and L. J. Richards. 1995. The influence of error on population estimates from catch-age models. Canadian Journal of Fisheries and Aquatic Sciences 52:20632077.

Sharov, A. F., J. H. Vølstad, G. R. Davis, B. K. Davis, R. N. Lipcius, and M. M. Montane. 2003. Abundance and exploitation rate of the blue crab (Callinectes sapidus) in Chesapeake Bay. Bulletin of Marine Science 72: 543-565.

Sheehy, M. R. J., R. C. A. Bannister, J. F. Wickins, and P. M. J. Shelton. 1999. New perspectives on the growth and longevity of the European lobster (Homarus gammarus). Canadian Journal of Fisheries and Aquatic Sciences 56:1904-1915.

Siddeek, M. S. M. 1991. Estimation of natural mortality of Kuwait's grooved tiger prawn Penaeus semisulcatus (de Haan) using tag-recapture and commercial fisheries data. Fisheries Research 11:109-125.

Siddeek, M. S. M., L. J. Watson, S. F. Blau, and H. Moore. 2002. Estimating natural mortality of king crabs from tag recapture data. Pages 51-75 in A. J. Paul, E. G. Dawe, R. Elner, G. S. Jamieson, G. H. Kruse, R. S. Otto, B. SainteMarie, T. C. Shirley, and D. Woodby, editors. Crabs in cold water regions: biology, management, and economics. University of Alaska Sea Grant College Program, AK-SG-02-01, Fairbanks.

Simpfendorfer, C. A. 1999a. Mortality estimates and demographic analysis for the Australian sharpnose shark, Rhizoprionodon taylori, from northern Australia. U.S. National Marine Fisheries Service Fishery Bulletin 97:978-986.

Simpfendorfer, C. A. 1999b. Demographic analysis of the dusky shark fishery in southwestern Australia. Pages 149-160 in J. A. Musick, editor. Life in the slow lane: ecology and conservation of long-lived marine animals. American Fisheries Society, Symposium 23, Bethesda, Maryland.

Smith, S. G., and E. S. Chang. 2007. Molting and growth. Pages 197-254 in V. S. Kennedy and L. E. Cronin, editors. The blue crab Callinectes sapidus. University of Maryland Sea Grant College, College Park.

Tagatz, M. E. 1968. Biology of the blue crab, Callinectes sapidus Rathbun, in the St. Johns River, Florida. U.S. National Marine Fisheries Service Fishery Bulletin 67:17-33.

Tanasichuk, R. W. 2000. Age-specific natural mortality rates of adult Pacific herring (Clupea pallasi) from southern 
British Columbia. Canadian Journal of Fisheries and Aquatic Sciences 57:2258-2266.

Thomas, J. C. 1973. An analysis of the commercial lobster (Homarus americanus) fishery along the coast of Maine, August 1966 through December 1970. NOAA Technical Report NMFS SSRF-667.

Van Engel, W. A. 1958. The blue crab and its fishery in Chesapeake Bay: part 1-reproduction, early development, growth, and migration. Commercial Fisheries Review 20:6-17.

Vetter, E. F. 1988. Estimation of natural mortality in fish stocks: a review. U.S. National Marine Fisheries Service Fishery Bulletin 86:25-43.

Wang, Y.-G. 1999. A maximum-likelihood method for estimating natural mortality and catchability coefficient from catch-and-effort data. Marine and Freshwater Research 50:307-311.

Wang, Y.-G., and N. Ellis. 2005. Maximum likelihood estimation of mortality and growth with individual variability from multiple length-frequency data. U.S. National Marine Fisheries Service Fishery Bulletin 103:380-391.

Waters, D. S., R. L. Noble, and J. E. Hightower. 2005. Fishing and natural mortality of adult largemouth bass in a tropical reservoir. Transactions of the American Fisheries Society 134:563-571.

Williams, E. H. 2002. The effects of unaccounted discards and misspecified natural mortality on harvest policies based on estimates of spawners per recruit. North American Journal of Fisheries Management 22:311-325.

Xiao, Y., and P. McShane. 2000. Estimation of instantaneous rates of fishing and natural mortalities from markrecapture data on the western king prawn Penaeus latisulcatus in the Gulf St. Vincent, Australia, by conditional likelihood. Transactions of the American Fisheries Society 129:1005-1017.

Xu, X., J. M. Bishop, H. M. A. Mohammed, and A. H. Alsaffar. 1995a. Estimation of the natural mortality rate of green tiger prawns Penaeus semisulcatus (de Hann, 1844) in Kuwait waters using relative abundance data. Journal of Shellfish Research 14:179-184.

Xu, X., H. M. A. Mohammed, A. Y. Al-Ghunaim, and F. AlYamani. 1995b. Temporal variability in natural mortality of green tiger prawns, Penaeus semisulcatus, in Kuwait waters. Journal of Shellfish Research 14:337-340.

Zheng, J., M. C. Murphy, and G. H. Kruse. 1995a. A lengthbased population model and stock-recruitment relationships for red king crab, Paralithodes camtschaticus, in Bristol Bay, Alaska. Canadian Journal of Fisheries and Aquatic Sciences 52:1229-1246.

Zheng, J., M. C. Murphy, and G. H. Kruse. 1995b. Updated length-based population model and stock-recruitment relationships for red king crab in Bristol Bay, Alaska. Alaska Fishery Research Bulletin 2:114-124.

Zheng, J., M. C. Murphy, and G. H. Kruse. 1997a. Analysis of harvest strategies for red king crab, Paralithodes camtschaticus, in Bristol Bay, Alaska. Canadian Journal of Fisheries and Aquatic Sciences 54:1121-1134.

Zheng, J., M. C. Murphy, and G. H. Kruse. 1997b. Alternative rebuilding strategies for the red king crab Paralithodes camtschaticus fishery in Bristol Bay, Alaska. Journal of Shellfish Research 16:205-217.

Zheng, J. 2003. Uncertainties of natural mortality estimates for eastern Bering Sea snow crab, Chionoecetes opilio. Fisheries Research 65:411-425. 